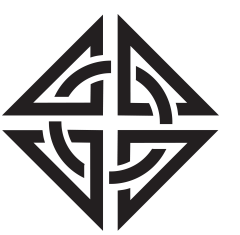

SCIENTIA
Sharif University of Technology

Scientia Iranica

Transactions D: Computer Science \& Engineering and Electrical Engineering

http://scientiairanica.sharif.edu

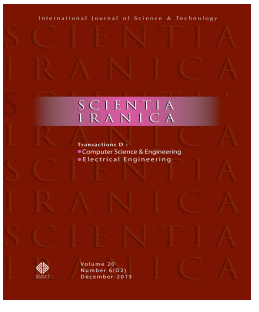

\title{
Design and optimization of tubular linear permanent-magnet generator with performance improvement using response surface methodology and multi-objective genetic algorithm
}

\author{
S. Arslan ${ }^{\mathrm{a}}$, O. Gürdal ${ }^{\mathrm{b}}$, and S. Akkaya $\mathrm{Oy}^{\mathrm{c}, *}$ \\ a. Department of Electrical and Electronics Engineering, Harran University, Urfa, 63400, Turkey. \\ b. Department of Electrical and Electronic Engineering, Faculty of Technology, Gazi University, Ankara, Turkey. \\ c. Fatsa Faculty of Marine Sciences, Ordu University, 52400, Turkey.
}

Received 24 December 2017; received in revised form 13 July 2018; accepted 29 October 2018

\author{
KEYWORDS \\ Linear generator; \\ Permanent magnet; \\ Finite element; \\ Multi-Objective \\ Genetic Algorithm \\ (MOGA); \\ Optimization.
}

\begin{abstract}
Linear generators are electric machines which generate electrical energy from linear movement. Since these machines can lift gear wheel or power train, they are nowadays widely used. Considering the fact that the working areas of these machines differ with speed and power characteristics, this study deals with the design and optimization of tubular linear generator for free piston practices. The design considered response surface optimization through variables that were acquired by sizing via the interface. The correlation between the determined design variables and the magnitude of the generator output was examined. In addition, the obtained amounts were used for objective functions of increasing efficiency, decreasing overall volume, and improving general performance and the optimum values were found by using Multi-Objective Genetic Algorithm (MOGA). Initial and optimum design data were compared by ANSYS Maxwell 2D. With overall performance improvement, $22.78 \%$ decrease in total mass and $11.7 \%$ decrease in cost were observed. In addition, a prototype for the linear generator was created in line with the initial geometry data and applied by the crank slider mechanism.
\end{abstract}

(C) 2020 Sharif University of Technology. All rights reserved.

\section{Introduction}

Considering the vast usage area of linear generators, e.g., free piston applications, wave energy, stirling system, shock absorbers, vibrators, compressors, mobile chargers, vibration energy harvesting devices, mobile lighting appliances, and space applications, the stud-

\footnotetext{
*. Corresponding author. Tel.: +9(0 414) 31830 00;

Fax: +9(0 414) 3183228

E-mail addresses: serdalarslan@harran.edu.tr (S. Arslan);

og.osman.gurdal@gmail.com (O.Gürdal);

sibelakkayaoy@gmail.com (S. Akkaya Oy)
}

doi: $10.24200 /$ sci. 2018.50093 .1506 ies on these generators have experienced increasing development day by day. Since linear machines are generated from rotating machines, their working principles are not different. However, they are different in terms of geometric structures, design equality, and methods. As it is well known, electric machine designers should consider designing by taking demands such as efficiency, total weight or local weight, cost, power density, etc. into account. In order to meet these goals, designers generally use optimization methods, e.g., pattern search, sequential nonlinear programming, Genetic Algorithm (GA), Response Surface Methodology (RSM), Monte Carlo simulation, etc., in package programs. ANSYS Maxwell is an instance that uses Fi- 
nite Element Method (FEM) the validity and reliability of which have been proven in the literature. Dalcali and Akbaba [1] examined the effect of parametric variation of pole arc offset distance on the performance of a permanent-magnet synchronous generator. Bouloukza et al. [2] performed optimization by using Monte Carlo method. They showed that there was a good agreement between the ANSYS Maxwell 2D calculations and the analytically calculated values of the optimum design of slotted Halbach Permanent-Magnet Synchronous Motor (PMSM). Qinghua et al. [3] performed the optimization of PMSM by using RSM and developed the prototype of the motor. They showed that the numerical results obtained through this optimization method and the application results matched. Abbaszadeh et al. [4] performed the optimization of cavity gap and slide in order to decrease the cogging torque with the help of RSM in brushless DC (BLDC) electric motor. In the cogging torque of the optimized motor, a significant decrease was seen in the simulation results by FEM. Jolly et al. [5] described their work on the design optimization of PMSMs using RSM and GAs. Ghasemi [6] used RSM to reduce the stroke force of surface magnet synchronous motor. The results showed that the optimum values of RSM were more efficient than those of the GA and particle swarm optimization in cogging torque reduction. Yu et al. [7] examined the effects of stator and rotor sizing variables of embedded PMSM on cogging torque by RSM. They made initial and optimum motor comparisons. Bremner [8] examined the effects of the basic geometrical proportions of embedded PMSM on the machine performance by RSM. Jabbar et al. [9] changed the rotor dimensions of embedded synchronous motor and performed optimization by using RSM and GA. Abbaszadeh et al. [10] examined the effects of the basic geometrical proportions of surface-insert permanentmagnet synchronous machine on machine performance by RSM. Arehpanahi and Kashefi [11] used magneto static FEM analysis and RSM to reduce cogging torque in interior PMSM. Arslan et al. [12] performed the optimization of a torus-type axial flux machine by using RSM. They observed that the general performance of the machine was maximized and the cogging torque and weight continued to decrease. Saha et al. [13] stated that efficiency improvement could be effectively achieved by designing the optimization of line-start permanent-magnet motor rotor structure using the RSM. Ahn et al. [14] proposed the approach as an efficient way to improve the performance of optimally designed permanent magnetic actuator and to reduce the number of experiments. The optimum design of the dual-permanent-magnet-excited machine was investigated by Jian et al. using RSM [15]. Hasanien et al. [16] performed optimization by using RSM and GA to improve the weight and thrust of transverse flux linear motor. Pourmoosa and Mirsalim [17] presented a low-speed single-sided linear induction motor design. They performed optimization by using RSM to decrease motor weight and increase thrust. They found that simulation and application data matched to a great extent. In our previous studies on linear generator, Arslan et al. [18] constructed a linear generator model through ANSYS Maxwell with analytical equations designed in MATLAB GUIDE. They carried out surface magnet tubular linear generator design and optimization. In line with the objective functions they determined, they used pattern research algorithm and obtained optimum sizing. Arslan et al. [19] examined magnetic flux density of the change in stator and rotor parts of the linear generator. Arslan and Oy [20] performed inset magnet tubular linear generator design and optimization. They used GA and Sequential Nonlinear Programming to reduce the cogging force. Wang et al. [21] performed optimization of tubular linear motor by means of decomposition-based multiobjective differential evolution particle swarm. Using Multi-Objective Genetic Algorithm (MOGA) alone can stretch to the area near an optimal Pareto front; however, it requires more computing time than the multiobjective optimization approach does. Parallelization causes a considerable decrease in computing time at each flowchart stage [22]. In this study, the software ANSYS Maxwell 2D was used in the calculations for the design of the tubular linear generator. The effects of sizing variables of the tubular linear generator on output variables were examined by means of correlation analysis. In addition, ANSYS Workbench RSM and MOGA were used to obtain optimum sizing in line with the objective functions determined. The initial design and the design obtained by optimization were compared using FEM.

\section{Analysis of the correlation between the variable parameters of the generator and efficiency, power out, weight, cost, and cogging torque}

Regression is an approach to modeling the relationship between two or more variables functionally. The value of the variable $y$ is estimated for the values of the independent variable $x$. Correlation is used to see whether there is relationship between two numerical variables, and if there is, to see the direction and size of this relationship. The mathematical model of the tubular linear generator (Figure 1) is written in MATLAB GUI. Analytical sizing data are given in Table 1.

It is vital to identify the parameters that will have direct effect on the performance of the generator in the optimization process, since incorrectly chosen design variable(s) has an undesirable influence on the success of optimization. In addition, the determined 


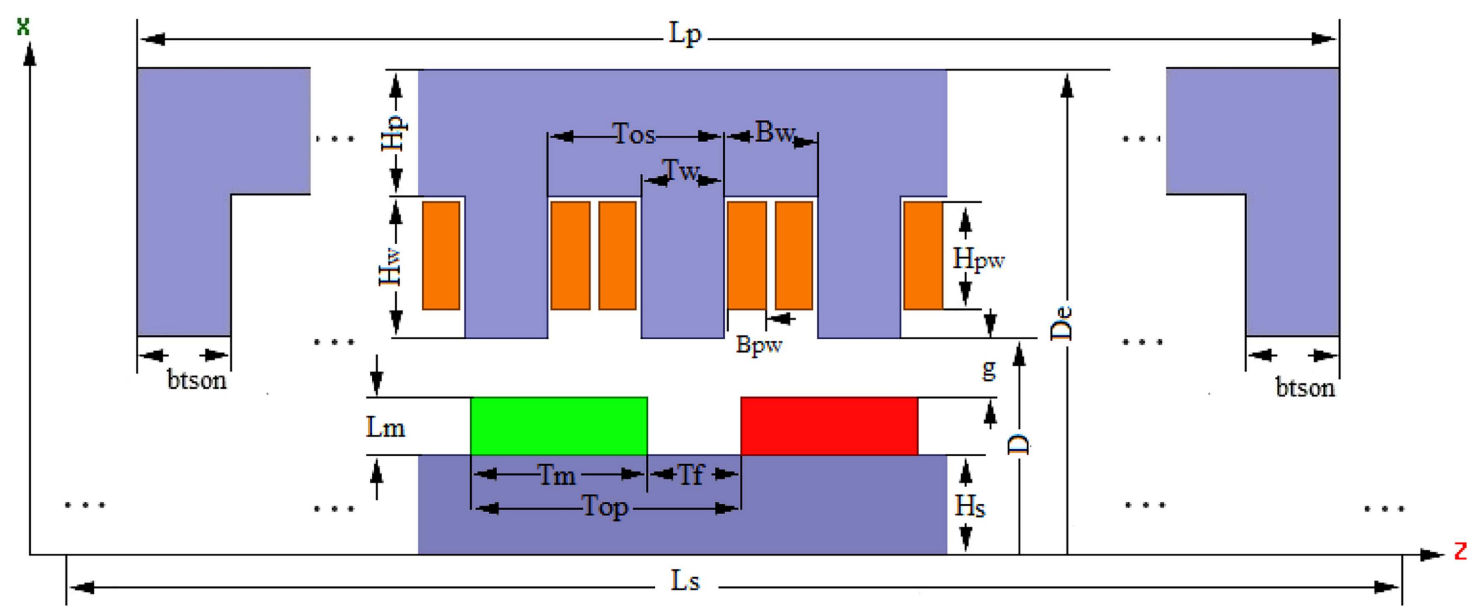

(a)

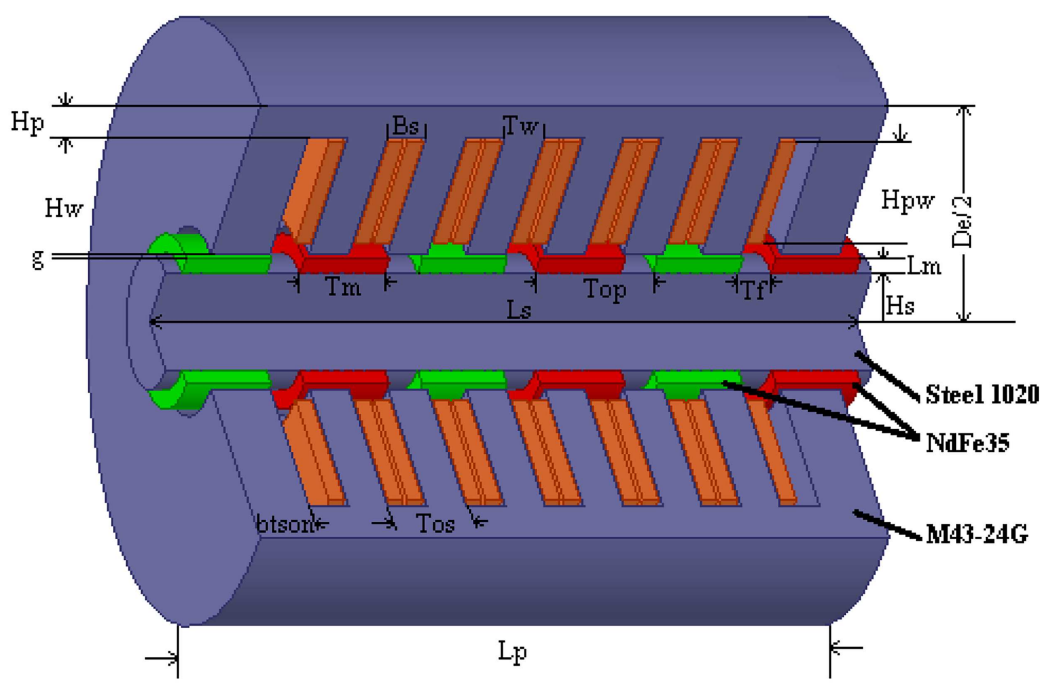

(b)

Figure 1. (a) 2D and (b) 3D representation of geometrical sizing of tubular linear generator.

Table 1. Generator input design parameters.

\begin{tabular}{lcclcc}
\hline \multicolumn{1}{c}{ Parameter } & Value & Unit & \multicolumn{1}{c}{ Parameter } & Value & Unit \\
\hline Power & 600 & $\mathrm{VA}$ & Slot pitch & 0.01833 & $\mathrm{~m}$ \\
Frequency & 50 & $\mathrm{~Hz}$ & $\mathrm{Lm}$ & 0.005 & $\mathrm{~m}$ \\
Stroke & 0.0275 & $\mathrm{M}$ & $\mathrm{G}$ & 0.002 & $\mathrm{~m}$ \\
Rated speed & 2.75 & $\mathrm{~m} / \mathrm{s}$ & $\mathrm{Tm}$ & 0.0198 & $\mathrm{~m}$ \\
Shear stress & 2 & $\mathrm{~N} / \mathrm{cm}^{2}$ & Tw & 0.009166 & $\mathrm{~m}$ \\
Current density & 3 & $\mathrm{~A} / \mathrm{mm}^{2}$ & Hw & 0.04473 & $\mathrm{~m}$ \\
Induced voltage & 55 & $\mathrm{~V}$ & De & 0.160 & $\mathrm{~m}$ \\
Alfa $($ Tm/Top $)$ & 0.72 & - & Slot fill factor & 0.6 & - \\
Beta $(B w /$ Tos $)$ & 0.5 & - & A coil winding number & 76 & - \\
Slot/Pole & $6 / 4$ & - & Approximate cost of copper & 30 & $\mathrm{Tl}$ \\
Winding factor & 0.866 & - & Approximate cost of magnet & 250 & $\mathrm{Tl}$ \\
Lowest common multiplier & 12 & - & Approximate cost of steel & 10 & $\mathrm{Tl}$ \\
\hline
\end{tabular}


input variables should not be associated with each other, since this will lead to calculating the correlation between output parameters and input parameters. It is important to find out the correlation between input variables and output parameters and to find out to what extent an input variable explains the output parameter. In line with this objective, optimization process will be more successful with suitably defined input parameters. In addition, a brief look at the literature in this area reveals that, generally, designers of electric machines choose the parameters which have a firstdegree influence on the geometry of motor/generator. However, variables are generally considered to be inner diameter, outer diameter, and pole pitch ratio. In this study, primary length and primary inner diameter widths are regarded as stable. Primary variables are considered to be air gap width $(g)$, thickness of magnet $(\mathrm{Lm})$, slot-pitch ratio (Beta), pole-pitch ratio $(A l f a)$, and primary yoke flux density (Byp). In order to find out the correlation between these design variables and design output parameters, Maxwell 2D $r z$ linear generator model was developed by ANSYS Workbench. Geometric variables and dimension sizes were defined by design features. Control conditions were identified in Maxwell 2D $r z$. Input and output parameters (stroke, efficiency, power out, cost, volume, iron loss, etc.) were determined in the Maxwell 2D design research section. Parameter correlation analysis module was added. Research points were formed by the specified limits of input variables. Correlation analysis method was determined. Design samples were solved by the program until the specified calculation criterion was reached (Figure 4).

The correlation between input and output parameters is expressed in matrix form with variables which can be positive or negative, ranging between +1 and -1 . The relationship is inverse with a negative value (i.e., as the input variable increases, output decreases with respect to the unit coefficient). On the other hand, positive values indicate direct relationship (i.e., as the input variable increases, output increases
Table 2. Input variables and margins.

\begin{tabular}{cccc}
\hline $\begin{array}{c}\text { Input } \\
\text { variable }\end{array}$ & $\begin{array}{c}\text { Initial } \\
\text { design } \\
\text { value }\end{array}$ & $\begin{array}{c}\text { Search } \\
\text { points } \\
\text { (Min-Max) }\end{array}$ & Unit \\
\hline Alfa & 0.7 & $0.6-0.8$ & - \\
Beta & 0.5 & $0.4-0.6$ & - \\
$L_{m}$ & 0.005 & $0.004-0.006$ & $\mathrm{~m}$ \\
$g$ & 0.002 & $0.0015-0.0022$ & $\mathrm{~m}$ \\
Byp & 1.8 & $0.6-0.8$ & $\mathrm{~T}$ \\
\hline
\end{tabular}

with respect to the unit coefficient). The primary variables: $g, L m$, Beta, Alfa, Byp themselves and their correlation are expressed with corner elements, taking the value of +1 . The correlations between other variables can have positive or negative values categorized as follows [23]:

0-0.19, no correlation;

0.2-0.39, weak correlation;

0.4-0.69, moderate correlation;

0.7-0.89, strong (high) correlation;

$0.9-1$, very strong correlation.

Coefficient of determination, which is expressed as $R^{2}$, identifies how the total change in the dependent variable can be explained by the independent variable. $R^{2}$ differs between $0-1$. Values close to 1 show that a great part of the change in dependent variables is determined by independent variables [23].

According to the input design variables in Table 2, the correlations between analysis process efficiency, power out, approximate cost, and total volume are presented in Figure 3. In the analysis performed for stroke, the maximum, peak-to-peak, and root values of cogging force are defined as output variables. The correlations between input variables and stroke change are given in Figure 2.

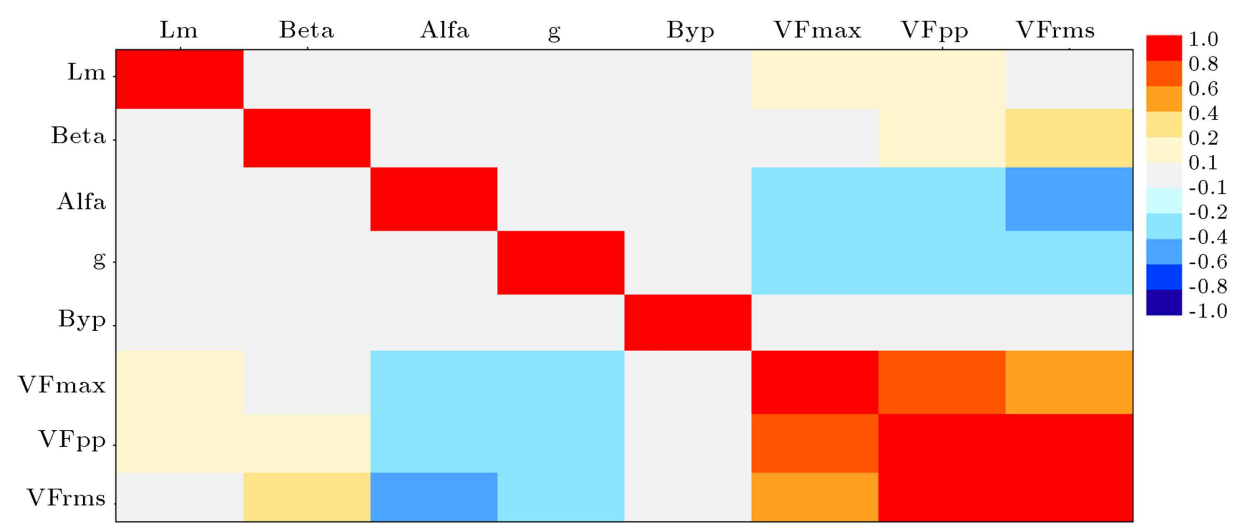

Figure 2. Correlation matrix between input variables and cogging force. 


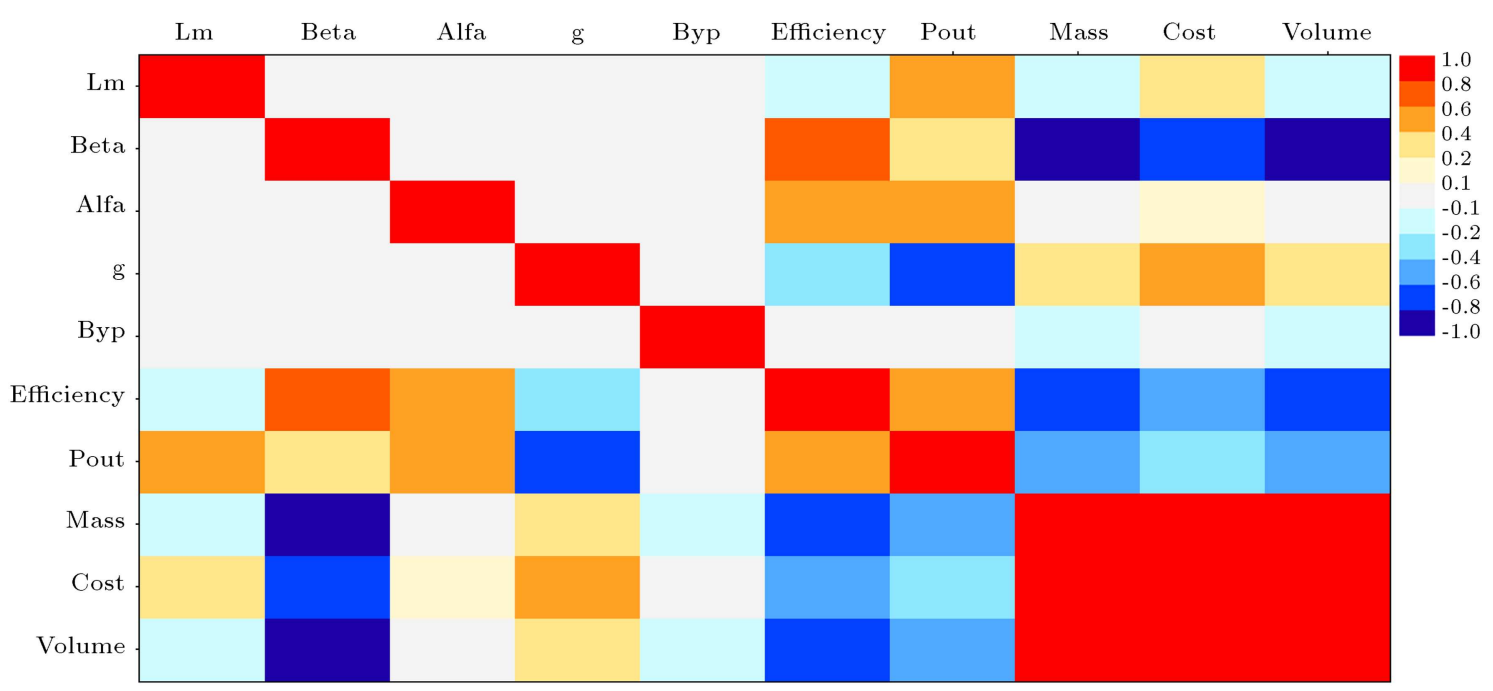

Figure 3. Correlation matrix between input variables and efficiency, power out, volume, cost, and mass.

As can be seen in Figure 2, while there is a moderate negative correlation between stroke and Alfa as well as $g$, the correlation between stroke and Beta is weak positive.

As observed in Figure 3, there is a very strong correlation between mass, cost, and volume. On the other hand, the correlations between Beta and mass, and volume and cost are strong negative. In addition, there is a high positive correlation between Beta and efficiency; moderate correlation between Alfa and efficiency; strong negative correlation between $g$ and power out; moderate correlation between $\mathrm{Lm}$ and power out and cost; and very weak correlation between Byp and mass, volume, and cost. While a moderate, strong, or very strong correlation with generator performance parameter is required by a variable to participate in optimization, there is no correlation between the specified design variables and generator performance.

\section{Optimization of stroke and objective functions by RSM}

Designers demand minimum cost when they want maximum efficiency and when they want maximum performance, they demand minimum weight. Mathematical modeling has great benefits when the opportunity to perform experimental work on the subject is limited or reaching results requires too many iterations. RSM, which is an application area of mathematical modeling, is one of the methods with partial factorial experimental or numerical application and it is a very important statistical method for the analysis of correlations between different results obtained with different factors.

RSM uses statistical and experimental methods together. It is a group of serial processing applied to optimizing the dependent variable among independent variables. This method assesses independent variables as parameters and dependent variables as responses or output. Tendency to maximum increase or decrease in order to reach the minimum or maximum level (maximum point desired) is the primary approach. The effects of independent variables on the response can be observed by decreasing the number of required experiments for optimization with RSM. While using RSM, it is important to choose the independent variables which are believed to influence the dependent variables the most for getting correct results. The choice of variables can be made through a mathematical model or correlation analysis. Primary data given in the literature (pole pitch ratio, slot pitch, etc.) and the ranges in which the variables can be measured are found. Model equations used in RSM can be firstor second-degree ones. In the electric machine studies conducted with RSM, second-degree model equations are preferred. Eq. (1) gives RSM design variables function and error:

$$
y=f\left(x_{1}, x_{2}, x_{3}, x_{4}, x_{5}, \cdots, x_{n}\right)+\varepsilon,
$$

where $y$ is the response of the system and $x_{n}$ represents the independent variables. Here, $y$ can be efficiency, power out, stroke, etc. Design variables are $L m, g$, alfabeta, Byp, and error $(\varepsilon)$. The difference between the observed and expected values of $y$ is given as the error:

$$
y=f(x)+\varepsilon .
$$

Response surface models are expressed as seconddegree polynomials, which include variables and their interactions.

$$
y=\beta_{0}+\sum_{i=1}^{n} \beta_{i} X_{i}+\sum_{i=1}^{n} \beta_{i i} X_{i}^{2}+\sum_{i=1}^{n} \sum_{j=1}^{n} \beta_{i j} X_{i} X_{j}+\varepsilon_{0},
$$


where $\beta_{0}$ is a fixed model; $\beta_{i}, \beta_{i i}$, and $\beta_{i j}$ are variable coefficients; and $x_{i}$ and $x_{j}$ are the coded independent variables. When a second-degree response surface model suitable for the variables is developed, the levels of $x_{1}, x_{2}, \cdots, x_{n}$, which optimize the estimated response variable, should be determined. This point, which optimizes the response variable (if any), is found by taking the partial derivatives according to the variables $x_{1}, x_{2}, \cdots, x_{n}$ and taking them equal to zero. The design generally used to reach the optimum point is central integrated or Box-Behnken experimental design. Both are second-degree models with second-degree terms, that is, a correlation beyond the linear approach between independent variables and the output values can be expressed. Figures 2 and 3 represent the relationship between ANSYS Workbench and correlation, RSM, and optimization of the parameters. In addition, design explorer establishes design points through input design variables defined in ANSYS Maxwell 2D $r z$ and given in Table 2. ANSYS Maxwell 2D $r z$ tool is added in ANSYS Workbench. By means of this tool, the primary sizes of the generator, limiting conditions, and analysis parameters are defined. Then, the parameter correlation tool is added to Workbench and correlation matrices between input and output variables are obtained. RSM tool is added and the solution is realized. Here, MOGA is chosen as the optimization method. The data obtained give the best result separately for each objective function (Table 3 ).

Table 3. Objectives of design.

\begin{tabular}{|c|c|c|c|}
\hline \multirow{2}{*}{ Design } & \multirow{2}{*}{ Parameter } & \multicolumn{2}{|c|}{ Objective } \\
\hline & & Type & Target \\
\hline \multirow{4}{*}{$\begin{array}{c}\text { Design } 1 \\
X_{1}=1 \\
X_{2}=0 \\
X_{3}=0\end{array}$} & $\eta$ & Maximize & - \\
\hline & & & \\
\hline & $P_{\text {out }}=600$ & Seek target & 600 \\
\hline & & & \\
\hline \multirow{4}{*}{$\begin{array}{c}\text { Design } 2 \\
X_{1}=0 \\
X_{2}=1 \\
X_{3}=0\end{array}$} & $\frac{1}{V}$ & Maximize & - \\
\hline & & & \\
\hline & $P_{\text {out }}=600$ & Seek target & 600 \\
\hline & & & \\
\hline \multirow{4}{*}{$\begin{array}{c}\text { Design } 3 \\
X_{1}=0 \\
X_{2}=1 \\
X_{3}=0\end{array}$} & $\frac{1}{C}$ & Maximize & - \\
\hline & & & \\
\hline & $P_{\text {out }}=600$ & Seek target & 600 \\
\hline & & & \\
\hline \multirow{2}{*}{$\begin{array}{c}\text { Design } 4 \\
X_{1}=1\end{array}$} & $\frac{\eta}{V \cdot J}$ & Maximize & - \\
\hline & & & \\
\hline$X_{2}=1$ & $P_{\text {out }}=600$ & Seek target & 600 \\
\hline$X_{3}=1$ & & & \\
\hline
\end{tabular}

The best results for each design (Table 4) are analyzed again in ANSYS Maxwell 2D $r z$. The obtained FEM results and the analytical data are compared in Table 5 . Figure 4 gives ANSYS Workbench and Maxwell 2D as well as the analysis and optimization process.

It is possible to use the MOGA option for both response surface optimization and direct optimization. In this study, it was used with response surface optimization. With MOGA, we can generate a new sample set or use an already existing set to provide an approach more refined than the screening method. It can deal with multiple goals and can be used for all types of input parameters. A fast and non-dominated sorting method, which is an order of magnitude faster than the conventional Pareto ranking methods, is Pareto ranking scheme. Lagrange multipliers and penalty functions are not required in this method, since constraint handling makes use of the same non-dominance principle with the same objectives. This makes it possible to rank feasible solutions higher than infeasible ones. In a separate sample set, the first Pareto front solutions are archived distinctly from the evolving sample set, ensuring that the Pareto front patterns already available from earlier iterations get minimal disruption. By changing the maximum allowable Pareto percentage property, the selection pressure (and, consequently, the elitism of the process) can be controlled to avoid premature convergence [24]. Figure 5 gives MultiObjective Genetic Algorithm (MOGA) flow diagram.

The initial population is employed to operate the MOGA algorithm. When MOGA is operated, it produces a new population through cross-over and mutation. Following the first iteration, each population is operated after having reached the number of samples specified by the number of samples per iteration property. MOGA proceeds to generate a new population. In the new population, design points are updated and optimization is validated for convergence. When either the maximum allowable Pareto percentage or the convergence stability percentage has been reached, convergence of MOGA takes place. The process continues to the next step if the convergence of MOGA does not take place. Optimization is validated for fulfillment of stopping criteria if it does not converge. In case of meeting the criterion of maximum number of iterations, the process stops without having reached convergence. However, if the stopping criteria are not met, in order to create a new population, MOGA is regenerated. MOGA generates a new population through stopping criteria. Until the convergence of optimization or fulfillment of the stopping criteria, validation is repeated in sequence. The optimization concludes if either of these cases occurs [23]. According to the graph in Figure 6, increase in Alfa and Beta increases efficiency and power out. An increase in $L m$ increases both power out and cost. Increase in Beta will 


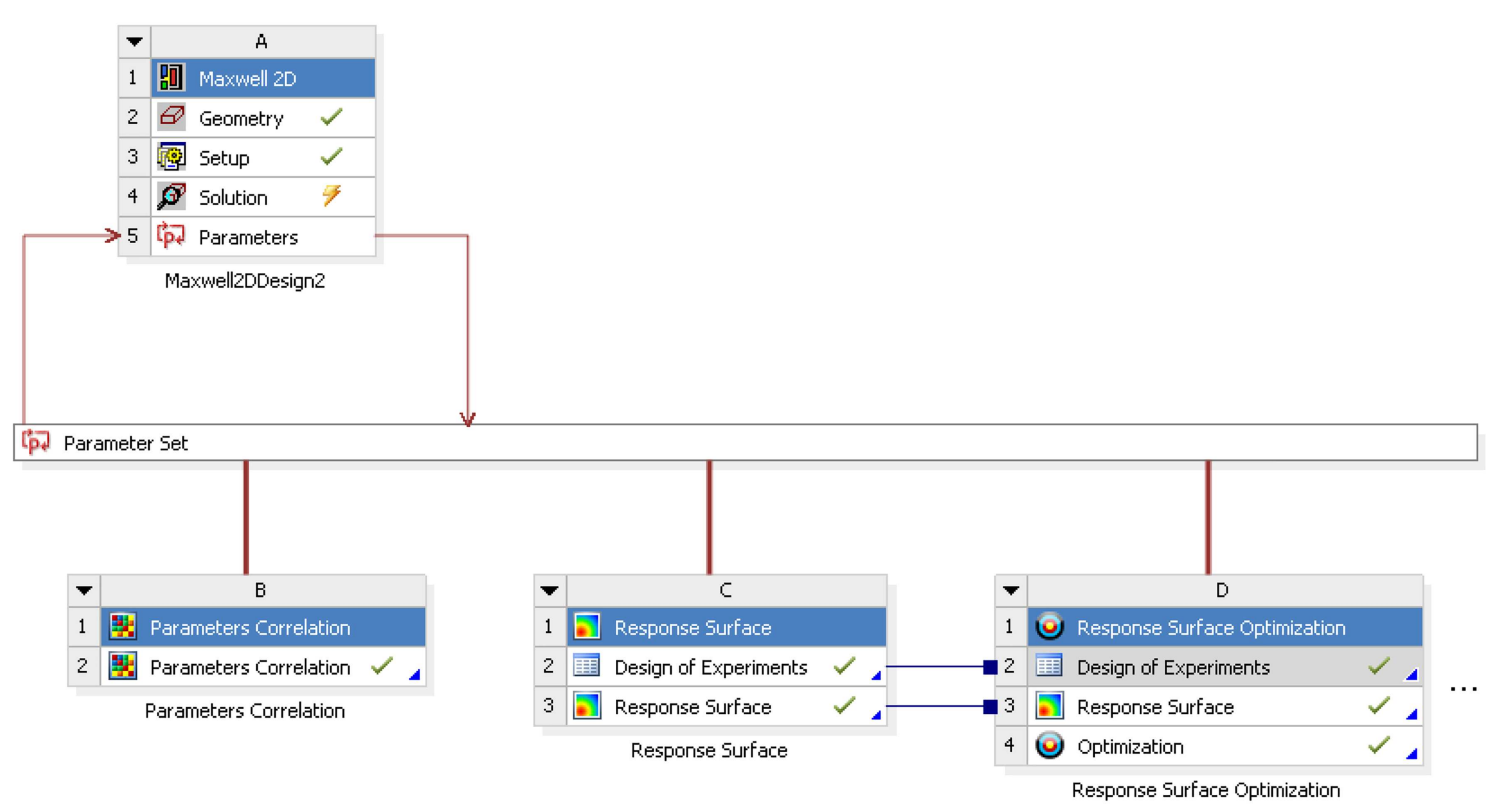

Figure 4. Response Surface Methodology (RSM) and optimization analysis process of tubular linear generator for an objective function with ANSYS Workbench.

Table 4. Comparison of analytical and numerical optimization results.

\begin{tabular}{cccccc}
\hline \multirow{2}{*}{ Input variable } & Initial design & Design 1 & Design 2 & Design 3 & Design 4 \\
\cline { 2 - 6 } & Analytical & FEM & FEM & FEM & FEM \\
\hline Lm & 0.005 & 0.00403 & 0.005524 & 0.0041038 & 0.005275 \\
Beta & 0.5 & 0.501 & 0.59486 & 0.59403 & 0.59913 \\
Alfa & 0.7 & 0.79033 & 0.63315 & 0.68248 & 0.68333 \\
$G$ & 0.002 & 0.002058 & 0.0015203 & 0.0015147 & 0.0017788 \\
Byp & 1.8 & 1.815 & 2.1121 & 2.0857 & 2.1652 \\
\hline
\end{tabular}

Table 5. Response Surface Methodology (RSM) optimization results.

\begin{tabular}{lccccc}
\hline \multirow{2}{*}{ Output parameters } & Initial design & Design 1 & Design 2 & Design 3 & Design 4 \\
\cline { 2 - 6 } & Analytical & FEM & FEM & FEM & FEM \\
\hline Moving weight (kg) & 2.38 & 2.51 & 2.37 & 2.55 & 2.39 \\
Total weight (kg) & 19.09 & 19.6 & 14.64 & 15.05 & 14.74 \\
Approximate cost (TL) & 405.6 & 406.1 & 348.9 & 331.25 & 357.82 \\
Power out (VA) & 579.7 & 589.9 & 589 & 582 & 601 \\
Efficiency & 0.856 & 0.88 & 0.82 & 0.85 & 0.841 \\
\hline
\end{tabular}

decrease weight, cost, and volume. Finally, an increase in Alfa also increases cost.

Analyses showed significant effects of the correlation between Beta and Alfa on efficiency, weight, and cost. Thus, it is important to determine the Beta and
Alfa rates correctly for tubular and flat linear machines. For initial parameters, it is suitable to choose Alfa between 0.68 and 0.73 and Beta between 0.45 and 0.55 . The change in magnet thickness with Alfa influences efficiency and cost significantly. Magnet thickness 


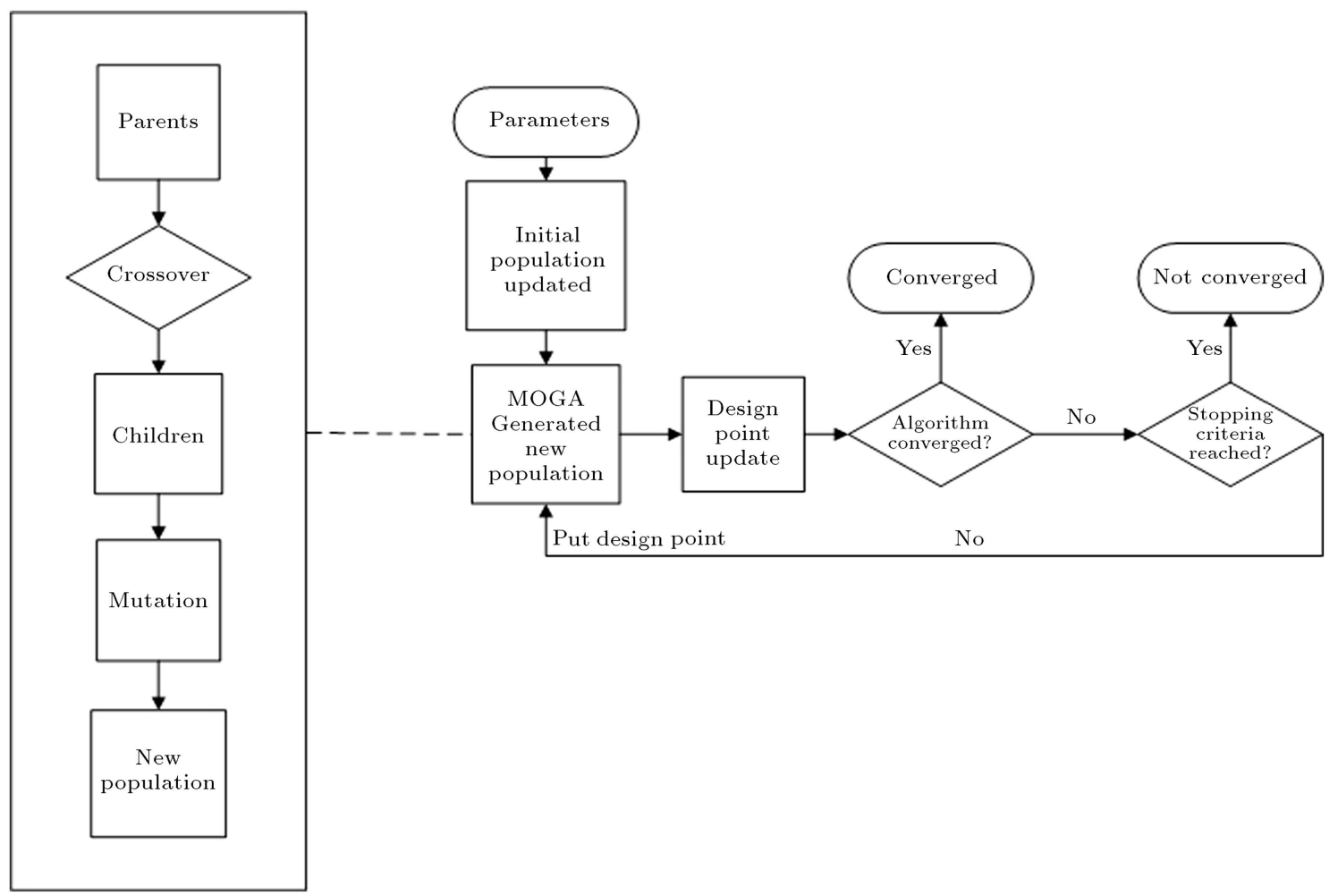

Figure 5. Multi-Objective Genetic Algorithm (MOGA) flow diagram.

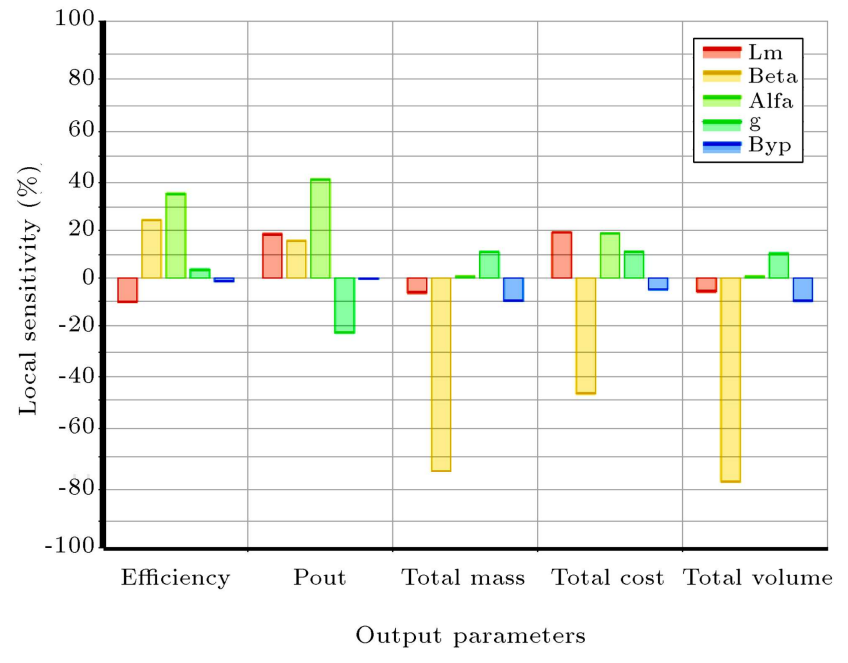

Figure 6. Local sensitivity changes of the basic variables in terms of output parameters.

differs with the magnetic equivalent circuit. While the thickness of the magnet decreases demagnetization risk, it also causes the core material to reach magnetic saturation. During the process of optimization by RMS, while benefit is derived from a feature, another feature is withdrawn. The conducted analyses showed that the change between magnet thickness and Beta was in the form of IF function (Figure 7). There is local minimum and maximum in the IF function. The optimum point of Beta can be taken as 0.5.
While the magnet thickness and change of Beta do not influence efficiency, significantly, they affect total generator weight and cost.

Figure 2 gives input variables and limits. Objective functions given in Eqs. (4) and (5) are defined separately. These objective functions are given as Design 1 efficiency maximum, Design 2 volume minimum, Design 3 cost minimum, and Design 4 general performance boost (Efficiency/(Volume* Current density)), as given in Table 3. For MOGA optimization, the power out for each objective function is $600 \mathrm{VA}$ :

$$
\begin{aligned}
& A . F 1=\frac{\eta^{X_{1}}}{V^{X_{2}} \cdot J^{X_{3}}} \quad \text { and } \quad P_{\text {out }}=600, \\
& A . F 2=\frac{\eta^{X_{1}}}{M^{X_{2}} \cdot J^{X_{3}}} \quad \text { and } \quad P_{\text {out }}=600, \\
& A . F 3=\frac{\eta^{X_{1}}}{C^{X_{2}} \cdot J^{X_{3}}} \quad \text { and } \quad P_{\text {out }}=600,
\end{aligned}
$$

where A.F1, A.F2, and A.F3 are objective functions; $\eta$ is efficiency; $V$ is volume; $M$ is weight; $C$ is cost; $J$ is current density; and $P_{\text {out }}$ is output power in the design decided by the desired values of $X_{1}, X_{2}$, and $X_{3}$. Here, in order to simplify the formula, the values of $X_{1}, X_{2}$, and $X_{3}$ are equalized to 0 or 1 . The simplified versions of objective functions given in Eqs. (4), (5), and (6) for the values of 0 and 1 for $X_{1}, X_{2}$, and $X_{3}$ and the target are given in Table 3 . Here, two objectives are defined 

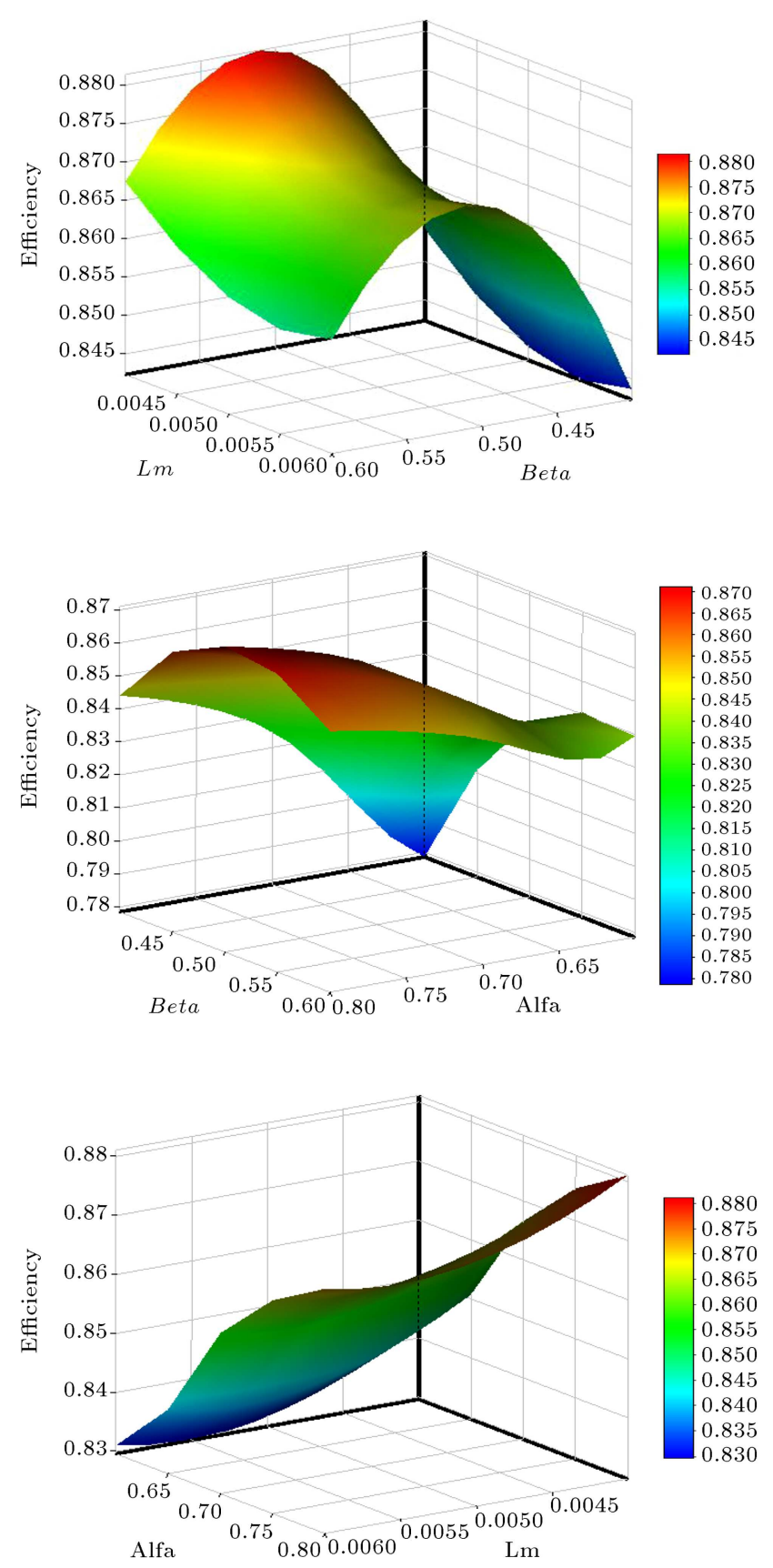

Figure 7. The influence of Lm-alfa-beta change on efficiency.

for each design in MOGA to maximize power out and functions for all targets.

Since the amount of the desired nominal value does not influence the optimization result in MOGA optimization method, the best proposed sizing data among the proposed 4 nominal values are given in Table 4.

Table 5 shows how much increase or decrease the obtained data show in terms of weight, cost, and efficiency in comparison with the initial design data. Here, while Design 1 shows $2.6 \%$ increase in the total

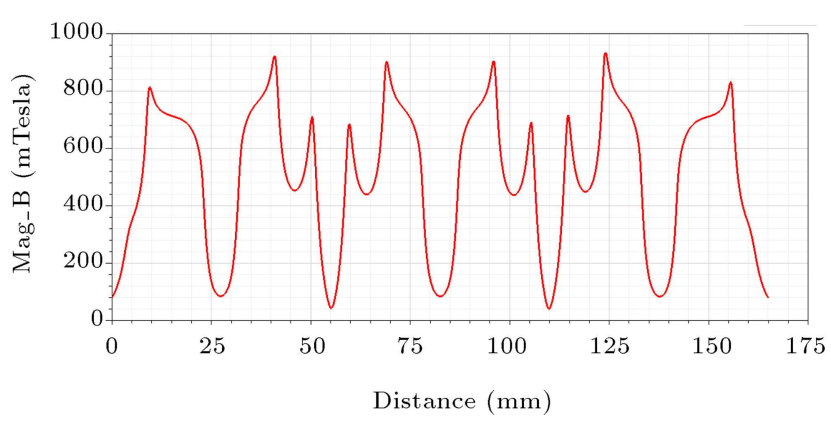

Figure 8. The distribution of the magnetic flux density on the length of the generator in ANSYS Maxwell 2D $r z$.

mass and no significant difference in cost, it provides $2.8 \%$ increase in efficiency. In addition to $23.3 \%$ decrease in the total mass and $13.9 \%$ decrease in cost, Design 2 shows $3.5 \%$ decrease in efficiency. With $21.1 \%$ decrease in the total mass and $18.3 \%$ decrease in cost, Design 3 makes no significant difference in efficiency. Finally, Design 4 leads to $22.7 \%$ decrease in the total mass and $11.78 \%$ decrease in cost. According to the analytical and numerical calculation results given in Table 5 for RMS optimization, the highest efficiency is seen in Design 1.

Results are given in Table 4, showing a good agreement between the FEM calculations and the analytically calculated values for the optimum design. The most suitable situation is seen with Design 4, in which there is a significant decrease in mass and cost and very little change in efficiency. In line with the design data given in Table 1, calculations of linear generator were made in the interface [19]. However, when the size of the magnet obtained from MOGA results was considered, it was difficult to produce magnets, specifically. Thus, generator geometry was established based on the initial design geometry data.

The distribution of the magnetic flux density on the length of the generator in ANSYS Maxwell 2D rz can be seen in Figure 8. The images of crank slider mechanism are given in Figure $9(\mathrm{a})$, (b), and (c). M43-24G geometry and magnetic rotor piece with iron sheet for the prototype are given in Figure $9(\mathrm{~d})$ and (e). The prototype machine can be seen in Figure 10, which is fabricated based on the initial design. In Figure 10, the generator is driven by the crank slider mechanism (Figures 9(b) and 10(b)) proper to a 4-pole asynchronous motor.

The results of the numerical analysis were compared with the testing prototype (unloaded) for $20 \mathrm{~Hz}$ driving frequency (Figure 11). Here, speed was calculated according to the crank sizes given. It was found that the results of the numerical analysis by ANSYS Maxwell and those of the application were in parallel to a great extent. In the experimental study, nominal working speed and frequency values were not reached due to mechanic vibration. 


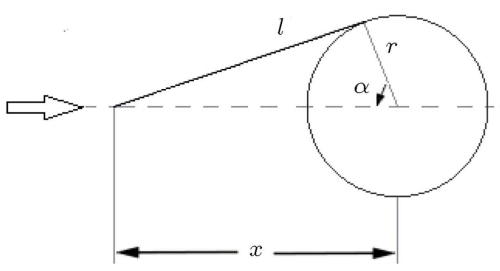

(a)

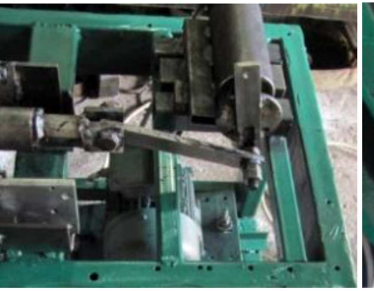

(b)

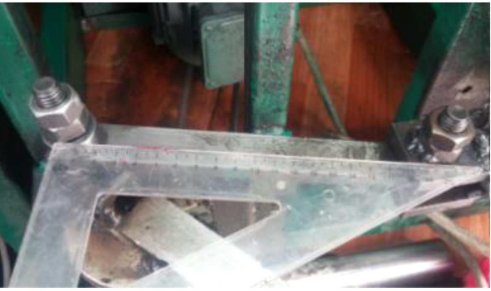

(c)

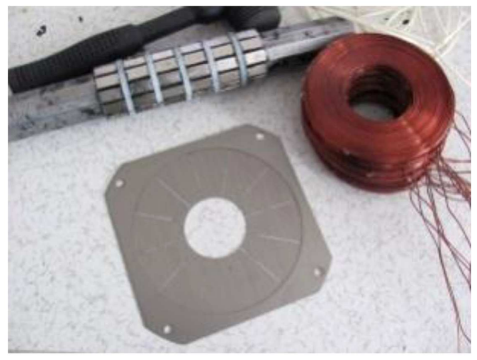

(d)

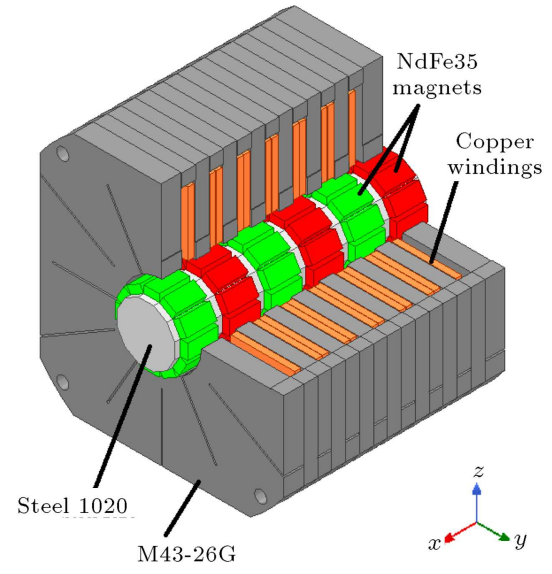

(e)

Figure 9. (a) Slider-crank mechanism dimensions: $r$ : radius of crank, $l$ : length of connecting rod, and $\alpha$ : rank angle. (b) Crank slider mechanism view in application. (c) Measurement of length of connecting rod. (d) Parts of the generator. (e) Generator view of the prototype.

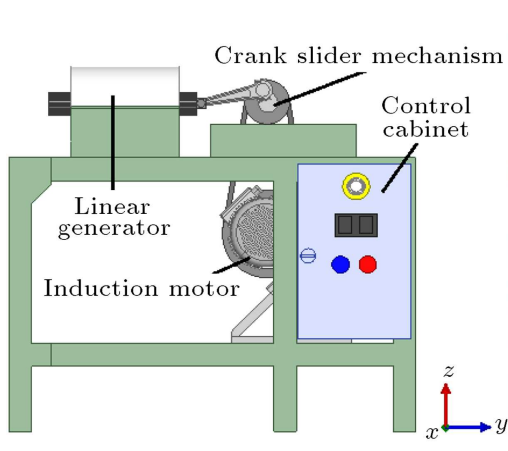

(a)

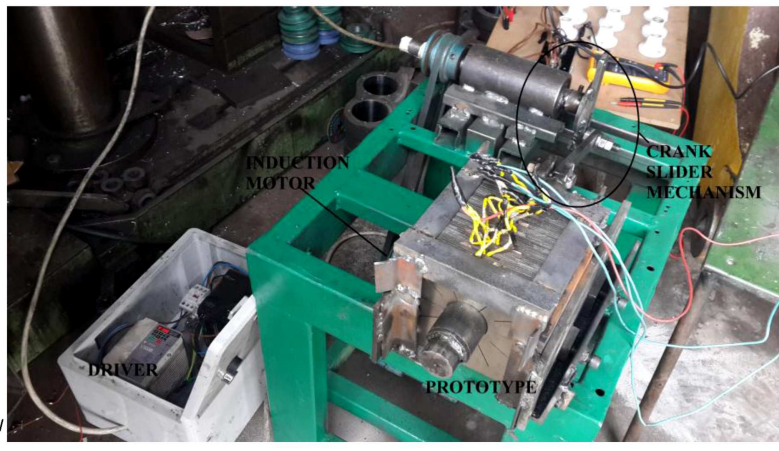

(b)

Figure 10. (a) Cranck slider mechanism. (b) Tubular linear permanent-magnet generator test rig.

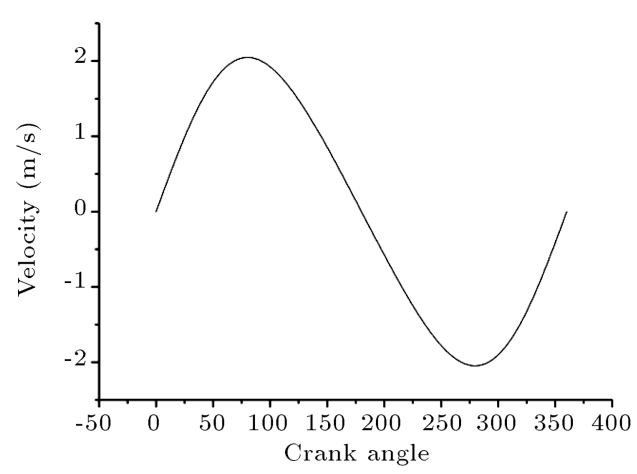

(a)

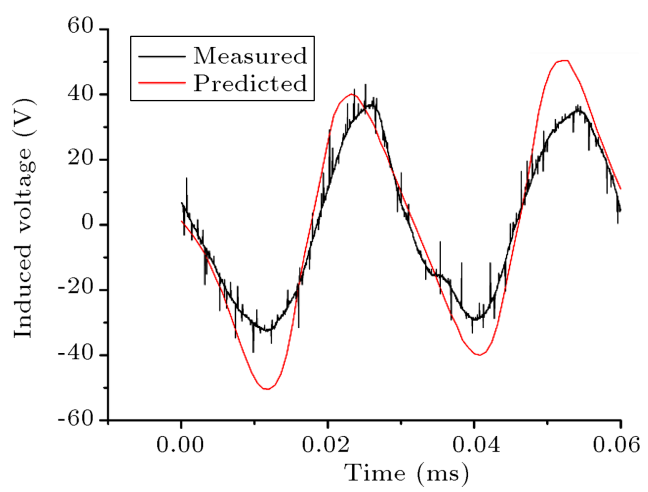

(b)

Figure 11. (a) Speed crank angle change. (b) The voltage induced in open-circuit phase winding. 


\section{Conclusion}

Nowadays, studies on free-piston motor-generator systems as range increasing units for electrical or hybrid vehicles have become very important. In free-piston motor-generator systems, it is vital to increase the efficiency of the electric energy produced in return for the fuel consumed. Thus, new approaches and methods for making the generator/motor design in these systems compact, light, and highly efficient are very important. In addition, since decreasing moving weight will increase mechanical frequency, it has a direct influence on generator performance.

In this study, sizing optimization was performed for free piston practices through Response Surface Methodology (RSM) by the analytical results of the tubular linear generator model. We tried to reach the constraint values by making continuous iterations in line with sizing equations and objective functions. These functions were aimed at increasing efficiency and decreasing cost, volume, and total mass. Objective functions determined through RSM were applied to the Multi-Objective Genetic Algorithm (MOGA) analysis. In addition, it was found that Design 4, which included general performance, did not cause significant change in moving weight and led to decreases by $1.75 \%$ in efficiency, $22.7 \%$ in mass, and $11.78 \%$ in cost. It was shown that RSM and the optimization method, which comprised MOGA, were successfully implemented.

\section{References}

1. Dalcali, A. and Akbaba, M. "Optimum pole arc offset in permanent magnet synchronous generators for obtaining lowest voltage harmonics", Scientia Iranica, Transaction D, Computer Science \& Engineering, Electrical, 24(6), pp. 3223-3230 (2017).

2. Ibtissam, B., Mourad, M., Medoued, A., et al. "Multiobjective optimization design and performance evaluation of slotted Halbach PMSM using Monte Carlo method", Scientia Iranica, D, Computer Science \& Engineering, Electrical, 25(3), pp. 1533-1544 (2018).

3. Qinghua, L.I.U., Jabbar, M.A., and Khambadkone, A.M. "Response surface methodology based design optimisation of interior permanent magnet synchronous motors for wide-speed operation", In Power Electronics, Machines and Drives, Second International Conference on, 2, Edinburgh, UK, pp. 546-551 (2004).

4. Abbaszadeh, K., Alam, F.R., and Saied, S.A. "Cogging torque optimization in surface-mounted permanentmagnet motors by using design of experiment", Energy Conversion and Management, 52(10), pp. 3075-3082 (2011).

5. Jolly, L., Jabbar, M.A., and Qinghua, L. "Design optimization of permanent magnet motors using response surface methodology and genetic algorithms", IEEE Transactions on Magnetics, 41(10), pp. 3928$3930(2005)$.
6. Ghasemi, A. "Cogging torque reduction and optimization in surface-mounted permanent magnet motor using magnet segmentation method", Electric Power Components and Systems, 42(12), pp. 1239-1248 (2014).

7. Yu, J.S., Cho, H.W., Choi, J.Y., et al. "Optimum design of stator and rotor shape for cogging torque reduction in interior permanent magnet synchronous motors", Journal of Power Electronics, 13(4), pp. 546$551(2013)$.

8. Bremner, R.D. "Rapid optimization of interior permanent magnet (IPM) machines using the response surface method and dimensionless parameters", Graduate Theses, Iowa State University, USA (2010).

9. Jabbar, M.A., Jolly, L., and Qinghua, L. "Design optimisation of permanent magnet motors using response surface analysis", In Digests 3rd International Conference on Electrical \& Computer Engineering, Dhaka, Bangladesh, pp. 28-30 (2004).

10. Abbaszadeh, K., Alam, F.R., and Teshnehlab, M. "Slot opening optimization of surface mounted permanent magnet motor for cogging torque reduction", Energy Conversion and Management, 55, pp. 108-115 (2012).

11. Arehpanahi, M. and Kashefi, H. "Cogging torque reduction of Interior Permanent Magnet Synchronous Motor (IPMSM)", Scientia Iranica, D, Computer Science \& Engineering, Electrical, 25(3), pp. 1471-1477 (2018)

12. Arslan, S., Kurt, E., Akizu, O., et al. "Design optimization study of a torus type axial flux machine", Journal of Energy Systems, 2(2), pp. 43-56 (2018).

13. Saha, S., Choi, G.D., and Cho, Y.H. "Optimal rotor shape design of LSPM with efficiency and power factor improvement using response surface methodology", IEEE Transactions on Magnetics, 51(11), pp. 1-4 (2015).

14. Ahn, H.M., Chung, T.K., Oh, Y.H., et al. "Optimal design of permanent magnetic actuator for permanent magnet reduction and dynamic characteristic improvement using response surface methodology", Journal of Electrical Engineering and Technology, 10(3), pp. 935943 (2015).

15. Jian, L., Shi, Y., Wei, J., et al. "Design optimization and analysis of a dual-permanent-magnet-excited machine using response surface methodology", Energies, 8(9), pp. 10127-10140 (2015).

16. Hasanien, H.M., Abd-Rabou, A.S., and Sakr, S.M. "Design optimization of transverse flux linear motor for weight reduction and performance improvement using response surface methodology and genetic algorithms", IEEE Transactions on Energy Conversion, 25(3), pp. 598-605 (2010). 
17. Pourmoosa, A.A. and Mirsalim, M. "Design optimization, prototyping, and performance evaluation of a lowspeed linear induction motor with toroidal winding", IEEE Transactions on Energy Conversion, 30(4), pp. 1546-1555 (2015).

18. Arslan, S., Gürdal, O., and Akkaya Oy, S. "The design, dimensioning and optimization of a 1 Kva tubular linear alternator", International Journal of Development Research, 6(12), pp. 10550-10559 (2016).

19. Arslan S., Gürdal O., and S.A. Oy "The determination of effects of primary and secondary geometry of tubular linear generator", IOSR Journal of Electrical and Electronics Engineering (IOSR-JEEE), 12(1), pp. 611 (2017).

20. Arslan, S., and OY, S.A. "Design and optimization of tube type interior permanent magnets generator for free piston applications", TEM Journal, 6(2), pp. 214221 (2017).

21. Wang, G., Chen, J., Cai, T., et al. "Decompositionbased multi-objective differential evolution particle swarm optimization for the design of a tubular permanent magnet linear synchronous motor", Engineering Optimization, 45(9), pp. 1107-1127 (2013).

22. Amdouni, I., El Amraoui, L., Gillon, F., et al. "Multiobjective approach developed for optimizing the dynamic behavior of incremental linear actuators", COMPEL: The International Journal for Computation and Mathematics in Electrical and Electronic Engineering, 33(3), pp. 953-964 (2014).

23. Alpar, R. "Uygulamalı İstatistik ve GeçerlilikGüvenirlik", Detay yayıncılık, pp. 1-668, Ankara, Turkey (2014).

24. http://www.webcitation.org/query?url=https $\% 3 \mathrm{~A} \%$ 2F\%2Ftr.scribd.com\%2Fdocument $\% 2$ F370055766\%2 FAnsys-Maxwell-18-Online-Help\&date=2018-07-09

\section{Appendix}

The application of the cosine theorem according to the triangle in the moving system in Figure 9(a) is:

$$
\begin{aligned}
& l^{2}=x^{2}+r^{2}-2 x r \cos \alpha, \\
& x^{2}-2 x r \cos \alpha=l^{2}-r^{2}, \\
& x^{2}-2 x r \cos \alpha+r^{2} \cos ^{2} \alpha=l^{2}-r^{2}+r^{2} \cos ^{2} \alpha, \\
& (x-r \cos \alpha)^{2}=l^{2}-r^{2}\left(1-\cos ^{2} \alpha\right),
\end{aligned}
$$

where:

$$
\sin ^{2} \alpha=1-\cos ^{2} \alpha \text {. }
$$

By taking the square root of two sides of the equality:

$$
\begin{aligned}
& x-r \cos \alpha=\sqrt{l^{2}-r^{2} \sin ^{2} \alpha}, \\
& x=r \cos \alpha+\sqrt{l^{2}-r^{2} \sin ^{2} \alpha} .
\end{aligned}
$$

$l$ is length and $r$ a crank radius, which is constant.
The crank angle $(\alpha)$ varies between $\left(0^{\circ}-360^{\circ}\right)$ and $x$ is the only variable that affects the piston position. At $\alpha=0^{\circ}$, the piston is in the top point and position size is $l+r$. At $\alpha=180^{\circ}$, the piston is in the bottom point and position size is $l-r$. Piston speed is a derivative of displacement:

$$
v=\frac{d x}{d t}
$$

Angular velocity is:

$$
\begin{aligned}
& \omega=\frac{d \alpha}{d t}, \\
& v=\frac{d x}{d \alpha} \cdot \frac{d \alpha}{d t}, \\
& v=\frac{d x}{d \alpha} \omega .
\end{aligned}
$$

If the position of Eq. (A.7) is derived according to the alpha:

$$
\begin{aligned}
\frac{d x}{d \alpha}= & -r \sin \alpha+\frac{1}{2}\left(l^{2}-r^{2} \sin ^{2} \alpha\right)^{-1 / 2} \frac{d}{d \alpha} \\
& \left(l^{2}-r^{2} \sin ^{2} \alpha\right), \\
\frac{d x}{d \alpha}= & -r \sin \alpha+\frac{1}{2 \sqrt{l^{2}-r^{2} \sin ^{2} \alpha}} \\
& \left(0-r^{2} 2 \sin \alpha \cos \alpha\right), \\
\frac{d x}{d \alpha}= & -r \sin \alpha+\frac{r^{2} \sin \alpha \cos \alpha}{\sqrt{l^{2}-r^{2} \sin ^{2} \alpha}} .
\end{aligned}
$$

According to Eqs. (A.11) and (A.14), the speed can be calculated as follows:

$$
v=\left[-r \sin \alpha-\frac{r^{2} \sin \alpha \cos \alpha}{\sqrt{l^{2}-r^{2} \sin ^{2} \alpha}}\right] x \omega .
$$

\section{Biographies}

Serdal Arslan was born in Bolu, Turkey, in 1983. $\mathrm{He}$ received the $\mathrm{MSc}$ and $\mathrm{PhD}$ degrees in Electrical Education from the Institute of Natural and Applied Sciences, University of Gazi, Ankara, Turkey, in 2011 and 2017, respectively. He worked as a Research Assistant at Hakkari University between 2010 and 2011. Then, he attended Harran University, where he is currently a lecturer in the Department of Electrical Technology. He has been working for many years in the field of computational electromagnetics. His research interests are in the areas of design, modelling, and analysis of electrical machines; optimized design of linear/rotary machines; and electromagnetic devices. 
Osman Gürdal received the BSc and MSc degrees in Electrical Education from the Technical Education Faculty of the University of Gazi, Ankara, Turkey, in 1985 and 1991, respectively. He received the $\mathrm{PhD}$ degree in Electrical and Computer Engineering from the University of Sussex, Brighton, UK, in 1994. After 27 years of academic life at the University of Gazi, he is now professor at the University of Bursa Orhangazi. His research interests are computer aided design, analysis, and simulation of electrical machines, magnetic circuits, and actuators as well as field theory.

Sibel Akkaya Oy received the BSc degree in Electrical Education from Dicle University, Turkey, in 2005 and the MSc degree in the same field from Firat University, Turkey, in 2007. Also, she received the PhD degree in Electrical Education from Gazi University, Turkey, in 2014. Her research focuses on the electrical machine design and renewable energy. 